\title{
AN INQUIRY INTO THE CAUSES OF INCREASING REGIONAL INCOME INEQUALITY IN THE UNITED STATES*
}

\author{
Orley M. Amos, Jr.*
}

\begin{abstract}
This paper explores alternative theoretical explanations of empirical evidence of increasing regional income inequality in the United States since the mid-1970s. Analysis indicates that conventional regional growth theories, including the neoclassical, export base, cumulative causation, and growth pole theories, explain increasing regional inequality by resorting to exogenous forces. Although each of the theories contains key relationships that provide a partial explanation of unbalanced growth and regional inequality, none of them is complete. The theory of long waves, long used in the study of economic cycles, then is examined. Key relationships contained in each of the regional growth theories are synthesized with the long wave explanation to generate a more complete theory of unbalanced regional growth and an endogenous explanation of increasing regional inequality.
\end{abstract}

\section{Introduction}

Unbalanced regional growth and its implications for the inequality of per capita regional income have been investigated theoretically and empirically by numerous authors over the past several decades, including Chenery (1962), Hughes (1961), Lasuen (1962), Williamson (1965), Dixon and Thirlwall (1975), Smith (1975), and Lande and Gordon (1977). A unifying theme of this literature has been the examination of the convergence of regional incomes and the decline in regional per capita income inequality. That phenomenon is generally expected in advanced, industrialized countries due to widely accepted implications of conventional theoretical analyses.

Early empirical studies of regional income differentials generally have supported expectations of convergence. Williamson (1965) found evidence of regional

This research was made possible by funding through the Dean's Excellence Fund, College of Business Administration, Oklahoma State University, in cooperation with the Southwest Regional Development Center. The valuable comments of two anonymous reviewers are acknowledged and appreciated; any errors remain the responsibility of the author.

-Professor of Economics and Kerr Professor of Economic Development, Oklahoma State University. convergence in the United States and several other highly developed countries. In a study of regional growth Borts (1960) also found support for convergence in the United States. Moreover, the Bureau of Economic Analysis regularly provides evidence of per capita income convergence among states. This evidence is exemplified by Friedenberg (1978) and Johnson and Friedenberg (1985).

Although regional income convergence is expected theoretically and has been empirically identified in earlier studies, a recent analysis by Amos (1988) provides evidence of diverging regional incomes and increasing regional inequality in the United States since the mid-1970s. While several theories, including the neoclassical, export base, cumulative causation, and growth pole theories, have been used to explain unbalanced regional growth, none satisfactorily explains these recent empirical observations. Conventional theories can explain decreasing regional inequality endogenously, but fail to provide endogenous explanations for increasing regional inequality.

This research explores an alternative explanation based on the proposition that development progresses in a wave-like manner with decades of sustained growth and prosperity, followed by nearly equal periods of stable, stagnant, or declining economic activity. This theory of long waves indicates that technological innovations induced by general economic conditions provide the impetus for the unbalanced regional growth that underlies increasing regional inequality.

\section{Regional Inequality in the United States}

Based on the inverted- $U$ pattern proposed by Kuznets (1955), regional inequality is expected to rise during early stages of development, then decline during latter stages. The extensive empirical analysis undertaken by Williamson (1965) clearly indicates a pattern of regional income convergence in the U. S., at least to the 1960s. However, more recent evidence suggests that regional inequality has been increasing in the U. S. since the 1970s.

Using a measure of inequality employed by Williamson (1965, p. 11), Table 1 indicates that although interstate inequality (the variation of per capita income among states), declined between 1932 and 1978, it increased from 1978 to 1985 . Inequality declined from a 
Table 1

Coefficients of Interstate Per Capita Income

Inequality in the United States, 1929-1985

\begin{tabular}{cccc}
\hline \hline Year & $\begin{array}{c}\text { Inequality } \\
\text { coefficient }\end{array}$ & Year & $\begin{array}{c}\text { Inequality } \\
\text { coefficent }\end{array}$ \\
\hline 1929 & 0.369 & 1959 & 0.184 \\
1930 & 0.389 & 1960 & 0.188 \\
1931 & 0.395 & 1961 & 0.186 \\
1932 & 0.410 & 1962 & 0.180 \\
1933 & 0.394 & 1963 & 0.177 \\
1934 & 0.369 & 1964 & 0.179 \\
1935 & 0.337 & 1965 & 0.165 \\
1936 & 0.344 & 1966 & 0.155 \\
1937 & 0.326 & 1967 & 0.153 \\
1938 & 0.329 & 1968 & 0.152 \\
1939 & 0.331 & 1969 & 0.156 \\
1940 & 0.331 & 1970 & 0.150 \\
1941 & 0.306 & 1971 & 0.150 \\
1942 & 0.269 & 1972 & 0.138 \\
1943 & 0.258 & 1973 & 0.128 \\
1944 & 0.236 & 1974 & 0.126 \\
1945 & 0.227 & 1975 & 0.128 \\
1946 & 0.236 & 1976 & 0.124 \\
1947 & 0.226 & 1977 & 0.121 \\
1948 & 0.209 & 1978 & 0.117 \\
1949 & 0.210 & 1979 & 0.120 \\
1950 & 0.215 & 1980 & 0.122 \\
1951 & 0.209 & 1981 & 0.121 \\
1952 & 0.204 & 1982 & 0.126 \\
1953 & 0.203 & 1983 & 0.131 \\
1955 & 0.200 & 1984 & 0.132 \\
1956 & 0.199 & 1985 & 0.138 \\
1956 & 0.198 & & \\
1957 & 0.197 & & \\
1958 & 0.181 & & \\
\hline \hline
\end{tabular}

Source: Obtained from Williamson $(1965$, p. 11) with recent years calculated by the author from Bureau of Economic Analysis per capita income and population data using the measure of regional income inequality of Williamson $(1965$, p. 11).

high of 0.410 in 1932 to a low of 0.117 in 1978 , supporting conventional expectations of decreasing regional inequality. This trend was reversed from 1979 to 1985 , increasing in each of the seven years, except 1981, rising to 0.138 in 1985.

An extension of the work of Williamson by Amos (1988) provides additional evidence of increasing regional inequality in an analysis of intrastate inequality. Whereas Table 1 presents measures of income variation among the states in the nation, measures of income variation among the counties in each state were used to analyze intrastate inequality. Table 2 reproduces results from Amos (1988) of time-series regression analyses for each of the 50 states from 1969 to 1983 based on the following equations:

$$
\begin{gathered}
\mathrm{Vi}=\alpha+\beta_{1} \mathrm{Y}_{\mathrm{i}} \\
\mathrm{Vi}=\gamma+\delta_{1} \mathrm{Y}_{\mathrm{i}}+\delta_{2} \mathrm{Y}_{\mathrm{i}}^{2}
\end{gathered}
$$

Where: $V_{i}=$ the inequality of per capita income among counties in the state, $Y_{i}=$ a measure of the average level of 
economic development in the state, either state per capita income or the year.

Table 2 classifies states based on the signs and significance of $\beta_{1}, \delta_{1}$, and $\delta_{2}$. The groups are: $I-\beta_{1}<0$; II $-\beta_{1}=0$; III $-\beta_{1}>0$, given that $\delta_{1}<0$ and $\delta_{1}>0$; and: $I^{*}-\beta_{1}<0 ; I^{*}-\beta_{1}=0$; III* $-\beta_{1}>0$, given $\delta_{1}=\delta_{2}=0$. Four of the six groups, I, II, III, and III*, indicate increasing regional inequality. Using per capita income to measure development, 31 of the 50 states show signs of increasing regional inequality, falling into one of the four relevant groups. Using the year to measure development, 27 states show signs of increasing regional inequality. Overall, 20 states show signs of increasing regional inequality for both measures and 37 states show signs for at least one of the measures. Only 13 of the states show no sign of increasing regional inequality. Table 2 also presents the estimated year in which equation (2) "bottoms out" for each state, indicated by MIN. Of the 35 states for which this calculation was performed 18 had minima between 1975 and 1977, with eight states in 1976 . These results are consistent with the evidence of increasing interstate inequality presented in Table 1.

Table 3 reproduces pooled cross-section, time series regression results for all 50 states from 1969 to 1983 from Amos (1988). The pooled equations indicate increasing regional inequality, falling into group I for both developmental proxies. The estimated year in which equation (2) reaches a minimum is 1975 , again indicating that regional inequality began increasing in the mid-1970s.

Although Tables 1 - 3 indicate that both interstate and intrastate regional inequality have increased since the mid-1970s, other evidence of increasing inequality exists.

Table 2

Intraregional Income Inequality

Time Series Alternatives for States Using BEA Data

\begin{tabular}{|c|c|c|c|c|c|c|c|}
\hline State & Income $^{\mathbf{a}}$ & Year & $\mathrm{MIN}^{\mathrm{b}}$ & State & Income & Year & MIN \\
\hline Alabama & $I^{*}$ & $I^{*}$ & 86 & Montana & (a) & (a) & - \\
\hline Alaska & II & $\mathrm{II}^{*}$ & - & Nebraska & (a) & $\mathrm{II}^{*}$ & - \\
\hline Arizona & $\mathrm{II}^{*}$ & II & 75 & Nevada & III & (a) & - \\
\hline Arkansas & II & II & 75 & New Hampshire & II & II & 77 \\
\hline California & III & III & 73 & New Jersey & III & III & 73 \\
\hline Colorado & II* & II & 76 & New Mexico & $\mathrm{III}^{*}$ & III & 74 \\
\hline Connecticut & II & $\mathrm{II}^{*}$ & 75 & New York & $\mathrm{II}^{*}$ & $\mathrm{II}^{*}$ & - \\
\hline Delaware & II & II* $^{*}$ & 76 & North Carolina & I & II & 76 \\
\hline Florida & III* & II* $^{*}$ & 75 & North Dakota & III & (a) & - \\
\hline Georgia & $\mathrm{II}^{*}$ & $\mathrm{II}^{*}$ & 73 & Ohio & III $^{*}$ & III $^{*}$ & 71 \\
\hline Hawaii & II* & II & 77 & Oklahoma & III* & $\mathrm{II}^{*}$ & - \\
\hline Idaho & (a) & $\mathrm{II}^{*}$ & - & Oregon & $\mathrm{II}^{*}$ & $\mathrm{II}^{*}$ & - \\
\hline Illinois & I & II & 77 & Pennsylvania & II & II & 76 \\
\hline Indiana & III & III* & - & Rhode Island & $\mathrm{II}^{*}$ & $\mathrm{II}^{*}$ & - \\
\hline Iowa & $\mathrm{II}^{*}$ & $\mathrm{I}^{*}$ & 72 & South Carolina & II & II & 76 \\
\hline Kansas & $\mathrm{II}^{*}$ & $\mathrm{II}^{*}$ & - & South Dakota & III* & (b) & - \\
\hline Kentucky & $\mathrm{II}^{*}$ & I & 77 & Tennessee & $\mathrm{II}^{*}$ & $\mathrm{II}^{*}$ & 75 \\
\hline Louisiana & II & $\mathrm{II}^{*}$ & 75 & Texas & III $^{*}$ & III* $^{*}$ & 60 \\
\hline Maine & II & II & 76 & Utah & $\mathrm{II}^{*}$ & III* & 73 \\
\hline Maryland & III $^{*}$ & III & 65 & Vermont & III & III & 73 \\
\hline Massachusetts & III* & III & 71 & Virginia & III & III & 72 \\
\hline Michigan & III* & $\mathrm{II}^{*}$ & - & Washington & $\mathrm{III}^{*}$ & $\mathrm{III}^{*}$ & 70 \\
\hline Minnesota & I & II & 76 & West Virginia & I & I & 79 \\
\hline Mississippi & $\mathrm{I}^{*}$ & $\mathrm{II}^{*}$ & 86 & Wisconsin & I & I & 79 \\
\hline Missouri & II & II & 76 & Wyoming & (b) & (b) & - \\
\hline
\end{tabular}

"An " indicates no significance in equation (2), $\delta_{1}=\delta_{2}=0$; I indicates $\beta_{1}<0$; II indicates $\beta_{1}=0$; III indicates $\beta_{1}>0$; (a) indicates a sign reversal in equation (2) with no significance in equation (1); and (b) indicates a sign reversal in equation (2) with $\beta_{1}>0$ in equation (1).

The estimated year in which equation (2) reaches its minimum value.

Source: Adapted from Amos (1988), Table 4. 
Table 3

Intraregional Income Inequality

Regression Results for Pooled BEA Data

\begin{tabular}{|c|c|c|c|c|c|c|}
\hline & Intercept & $\mathrm{Y}$ & $\mathrm{Y}_{2}$ & County Number & $\mathbf{R}^{2}$ & $\mathrm{MIN}$ \\
\hline \multirow[t]{2}{*}{ Income } & $\begin{array}{r}0.105^{c} \\
(11.039)^{d}\end{array}$ & $\begin{array}{l}0.0027^{b} \\
(1.793)\end{array}$ & $(14 . \overline{987})$ & $0.000653^{c}$ & .233 & - \\
\hline & $\begin{array}{r}0.240^{c} \\
(9.524)\end{array}$ & $\begin{array}{l}-0.0537^{c} \\
(-5.405)\end{array}$ & $\begin{array}{l}0.0057^{\mathrm{c}} \\
(5.746)\end{array}$ & $\begin{array}{r}0.000647^{c} \\
(15.215)\end{array}$ & .265 & $\$ 4,672$ \\
\hline \multirow[t]{2}{*}{ Year } & $\begin{array}{r}0.099^{c} \\
(6.074)\end{array}$ & $\begin{array}{r}0.000252 \\
(1.269)\end{array}$ & $(14 . \overline{915})$ & $0.000650^{c}$ & .231 & $\longrightarrow$ \\
\hline & $\begin{array}{r}0.966^{b} \\
(1.827)\end{array}$ & $\begin{array}{r}-0.022653^{\prime} \\
(-1.622)\end{array}$ & $\begin{array}{r}0.000151^{2} \\
(1.641)\end{array}$ & $\begin{array}{r}0.000650^{c} \\
(14.933)\end{array}$ & .234 & 1975 \\
\hline
\end{tabular}

Significant at the 0.20 level.

bSignificant at the 0.10 level.

eSignificant at the 0.05 level.

T $\mathrm{T}$-values in parentheses.

Source: Adapted from Amos (1988), Table 3.

Ray and Rittenoure (1987) identified regional income divergence among multi-state BEA regions beginning in 1981. Personal income inequality, as measured by the Gini coefficient, followed a declining trend from the late 1940s until the late 1960s, but has increased in the past decade (Census, 1984, p. 47). Studies by Maxwell and Peter (1988) and Maxwell and Hale (1988) indicate that inequality in Australia has increased since 1978. The existence of increasing interstate, intrastate, and personal income inequality in the United States, combined with increasing income inequality in Australia, implies the incidence of a previously unanticipated phenomenon.

Since interstate inequality in Table 1 isolates the variation among states (where the income in each state is the average of rural and urban incomes) and the intrastate variation in Tables 2 and 3 identifies the variation between rural and urban counties, there is no apriori reason to expect a consistent pattern of change in both. Differential rates of urban and rural growth will generate increasing intrastate inequality, but need not generate increasing interstate inequality. Moreover, differential rates of state growth, causing increasing interstate inequality, need not cause increasing intrastate inequality. The existence of both phenomena suggests a systematic, structural change in economic activity. The underlying cause of this process is not identified by existing theories of regional growth.

Results contrary to conventional expectations are especially revealing in light of the discussion by Alonso of regional inequality, personal inequality, and three other bell-shaped curves that experience convergence in the course of development: ". . it may be fruitful to look more closely at the right-hand side of these curves. Most of the analyses, theorizing, and debates encountered in this research deal with the rising portion and the inflection point of these curves, while the right-hand side generally has been left dangling and unexamined. In other words, attention has focused on the early and middle stages of development; the latter stages have been specified loosely or taken for granted (Alonso, 1980, p. 5)."

Unexpected evidence of increasing regional inequality on the right-hand side of the curve suggests that a more thorough investigation of the regional growth process is warranted. The lack of such investigation indicates why existing paradigms logically should not be expected to explain increasing regional inequality.

\section{Theoretical Explanations of Unbalanced Regional Growth}

Four theories have been applied to the study of unbalanced regional growth-the neoclassical, export base, cumulative causation and growth pole theories. Each of them captures important causal relationships underlying unbalanced regional growth, but none completely explains the phenomenon.

All four theories explain the increasing-decreasing pattern of regional income inequality. The neoclassical theory, based on the work of Solow (1956), Borts (1960), 
Borts and Stein (1964), Smith (1975), and Lande and Gordon (1977), employs standard assumptions of competitive markets, factor mobility, and utility-profit maximization to explain divergence through exogenous disequilibrating shocks, and convergence through equilibrating product and factor mobility. The export base theory, discussed by North (1955) and Hartman and Seckler (1967), explains both divergence and convergence through differential resource endowments, exogenous patterns of export demand, and the multiplier effect, with no implications for a systematic pattern of divergence or convergence. The cumulative causation theory, discussed by Myrdal (1957), Kaldor (1957, 1970), and Dixon and Thirlwall (1975), explains divergence and convergence through differential cumulative growth or decline caused by agglomeration economies and exogenous changes in export demand, with little implication for any systematic pattern. The growth pole theory, based on the work of Perroux (1955), Hirschman (1958), Hansen (1967), and Lasuen (1969), explains divergence through the backwash effect stimulated by exogenous technological innovation and convergence through the spread effect.

The primary deficiency of these theories is their reliance on exogenous factors to initiate divergence in the early stages of unbalanced growth. Although the neoclassical and growth pole theories explain the incidence of convergence after a period of divergence, consistent with the inverted- $U$, none of the theories offers an endogenous explanation for divergence after convergence. Their explanations for the increases in regional inequality observed in Tables 1-3 rely on exogenous changes in resource endowment, export demand, technological innovation, and/or political activity. The argument here is that the general incidence of increasing interstate, intrastate, and personal income inequality suggests the operation of a more fundamental, structural, and endogenous process. Since increasing regional inequality in the latter stages of development is a recently observed phenomenon, conventional explanations cannot be faulted as much for being wrong as for being incomplete. Each of the theories captures one or more important aspects of unbalanced regional growth, but none captures the complete process.

\section{The Process of Unbalanced Regional Growth}

It appears that more complete explanation of regional growth, including observed increases in regional income variation, could be initiated by examining the causal relationships specified in the four theories. Five key items are identified in this effort: factor mobility, the multiplier effect, innovation, capital formation, and transportation.
Factor mobility plays an explicit, integral role in regional income convergence in the neoclassical theory. It also surfaces in the spread and backwash effects of the growth pole and cumulative causation theories. All three theories recognize the importance of factor mobility in response to relatively higher returns, a relationship documented for labor (Greenwood, 1975, 1985). The main difference among the theories concerns the nature of aggregate production, and whether it experiences increasing, decreasing. or constant returns. While factor mobility generates convergence in the neoclassical theory through factor market equalization, and in the growth pole and cumulative causation theories through the spread effect, it generates divergence in the growth pole and cumulative causation theories through the backwash effect from agglomeration economies and increasing returns to scale.

The multiplier effect is a process that is highlighted by the export base theory, and it is included in the cumulative causation and growth pole theories. Cumulative, selfreinforcing growth or decline in the latter theories is attributable, in part, to the multiplicative relationship between export, motor industry, or leading sector activity and other activity. This relationship surfaces in both the spread and backwash effects, but it is differentiated by the location and direction of the initial stimulus.

Innovation plays a central role in growth pole theory, and it surfaces in the original discussion of economic base activity by North (1955). He argues that development is initiated, and further stimulated, as regions seek technological innovations that improve the comparative advantage of their export activity.

Investment and capital formation is critical in all four theories. The neoclassical theory is concerned with capital mobility and its formation in different regions. The export base theory centers around the multiplicative effect caused by investment and production in exporting activities. The backwash and spread effects of the cumulative causation and growth pole theories both are concerned with the causes and consequences of capital formation.

Transportation also surfaces to varying degrees in all four theories. Samuelson (1952), argues that in the neoclassical theory transportation is a barrier to factor mobility, but that regional income and factor payment convergence continues until regional differentials are matched by transportation costs between regions. North maintains that export base theory indicates that development is enhanced as regions improve their transportation systems to promote regional export activities. The backwash and spread effects of the cumulative causation and growth pole theories also are tied explicitly to the role of transportation. The lack of transportation systems and the resultant transportation costs inhibit interaction between more developed 
areas and those that are less developed, and contribute to the backwash effect in early stages of development. Improved transportation systems and lower costs facilitate greater interaction and contribute to the spread effect.

It is evident that each of the four theories has isolated critical aspects of regional economic growth. Since they view the process from different perspectives and concentrate on only a few of the relationships, none has combined these aspects into a comprehensive framework of regional growth. A general synthesis of these relationships should provide a more comprehensive framework that would permit an endogenous explanation of regional growth and the associated increasing inequalities.

\section{A Summary of Unbalanced Regional Growth}

The composition of the four theories discussed in this analysis offers an interpretation of the regional growth process. Regional growth initially is stimulated by technological innovations in export products that utilize the natural resources of a region, creating a growth pole and export base industry that stimulates growth throughout the region. The growth pole generates the backwash effect, through factor mobility, agglomeration economies, and the multiplier process, leading to cumulatively reinforcing growth at the expense of lesser developed areas. However, continued development brought about by the effort of each region to enhance its export base/growth pole leads to the diffusion of development to less developed areas through the spread effect. In the course of this process, private and public capital formation occurs, innovations are disseminated throughout the region, transportation systems are developed and improved, and regional inequality after increasing initially, subsequently declines.

This is an interpretive view of the process and numerous criticisms remain, including the influential role of government policies and whether the process is deterministic or descriptive, but it does highlight the central features of the theories discussed above. However, this is an incomplete view that offers a one-time explanation of the growth process. No further explanation is forthcoming once the disequilibrium is corrected, regional incomes converge, and innovations and development are diffused.

\section{Regional Growth and Long Waves}

All four theories discussed in this analysis identify critical aspects of regional growth, but each one takes a limited view of the regional growth process. Even a simple synthesis of the four theories fails to provide an endogenous explanation of increasing regional inequality. An alternative theory, which has had only limited exposure in the study of regional economies, offers a more complete explanation of the regional growth process and the phenomenon of increasing regional inequality. The long wave theory is based on the proposition that economic development progresses in a wave-like manner due to the periodic introduction and diffusion of technological innovations.

\section{Economic Cycles}

Mainstream macroeconomic analysis has dealt with cyclical economic activity since the classic work of Schumpeter (1939) on business cycles. Predating Schumpeter, other scholars investigated the cyclical nature of economic activity, including Kuznets (1930), Kondratieff $(1926,1935)$, and Kitchin (1923). Based on the work of these and others, Schumpeter argued that economic activity experiences several simultaneously occurring cycles with differing periods of duration. He identified three cycles that have been named after those most noted for their investigation: the Kitchin (3-5 years); Juglar (711 years); and Kondratieff (45-60 years) cycles. Quite often a fourth cycle is also added to this list, the Kuznets cycle of 15 to 20 years.

One explanation of the differing cycle lengths is investment in capital goods with alternative time frames for both production and depreciation. The Kitchin cycle occurs due to investment in business inventories and lasts approximately 4 years. The Juglar cycle involves investment in equipment, machines, and factories and lasts about 8 years. " The Kuznets cycle is based on investment in residential structures that generates a 20 -year cycle. The Kondratieff cycle lasts about 50 years because it involves investment in public infrastructure and transportation systems. Schumpeter argued that the underlying cause of these cycles is technological innovations that generate investment in different types of capital goods.

Explanations of cyclical activity rely on a multiplier process activated by increasing or decreasing investment in each of these types of capital goods. The process is cyclical because of the disequilibrium between desired capital and actual capital. If actual capital is less than desired capital, investment occurs, stimulating the multiplier effect which, due to the time lag in production, continues until actual capital exceeds desired capital. Depreciation of actual capital and increases in desired capital close the gap between desired and actual capital, stimulating further investment and the multiplier effect once more.

Klotz and Neal (1973), van Ewijk (1982), and Pope (1984) have tested empirically for the existence of cyclical economic activity, finding strong support for shorter cycles, but limited or no support for the longer Kondratieff 
cycle. However, van Duijn (1983), in the most complete theoretical and empirical evaluation of the Kondratieff cycle to date, finds significant evidence supporting the existence of Kondratieff cycles, using production data from several developed western economies, including the United States, the United Kingdom, Germany, Italy, and Sweden. While Kondratieff (1926) and Schumpeter (1939), found evidence for a Kondratieff cycle between approximately 1790 and 1845, van Duijn (1983, p. 143) was able to isolate Kondratieff cycles from 1845 to 1892 and from 1892 to 1948, with a third cycle over halfway completed, beginning in 1948 and peaking in 1973. An extension of past trends and more recent reports of economic activity indicate that this last cycle is likely to end around 1992.

\section{The Long Wave Theory}

The best presentation of the theory of long waves, contained in van Duijn (1983), builds on the works of Kondratieff $(1926,1935)$, Schumpeter (1939), Kuznets (1930), Rostow (1975), and Mensch (1979). Van Duijn identifies three main building blocks for the theory of long waves - innovation, innovation life cycles, and infrastructure investment.

According to van Duijn the long wave process is stimulated by the introduction of major product innovations-automobiles, railroads, airplanes, telephonesthat not only improve economic development, but also require substantial amounts of both private and public infrastructure capital. Moreover, product innovations that induce long waves are distinguished from other types of innovations due to the type of capital required. Major product innovations require substantial amounts of both private capital and public infrastructure capital. This is especially true of transportation systems. For example the 1845 to 1892 long wave can be tied to development of the railroad system in the United States, the 1892 to 1948 wave to automobile transportation, and the most recent wave starting in 1948 to air and the interstate automobile transportation system. In each case, massive amounts of capital investment were required to extend the transportation systems to all areas of the country.

The long wave theory indicates that major product innovations exhibit a life-cycle pattern that can be depicted by an S-shaped total product curve. The S-shaped lifecycle curve indicates that the innovations are not diffused throughout the economy instantaneously, but at different rates over time. The rate of diffusion, and consequently the growth of the innovating industry, are slow initially because the public is unfamiliar with the product. The rate increases as the innovation gains wider acceptance. And finally, the rate begins to decline when the innovation is nearly diffused and markets become saturated.

According to this theory, development proceeds in a wave-like manner because major product innovations not only stimulate investment and economic activity, but cluster periodically. Because they stimulate investment in both private and public infrastructure capital that stimulates further economic activity through the multiplier effect, the periodic clustering of major innovations drives the economy through alternating periods of expansion and decline. As product innovations simultaneously enter the rapidly growing phases of their life cycles, infrastructure investment is stimulated and the multiplier effect is set in motion. This generates a period of prosperity and the upswing of a long wave. The prosperity period lasts two to three decades due the time required for production of capital. When the innovations simultaneously reach the end of their life cycles, investment is reduced and, through the multiplier process, general economic activity slackens. This sends the economy into a period of stability, stagnation, or even into a depression. Saturation of the markets for the innovations causes the prosperity to end and starts the downswing of a long wave.

The critical factor underlying the cyclical upswings and downswings of long waves is the clustering of innovations. Van Duijn, building on the work of Mensch and Schumpeter, argues that innovations are induced by conditions in the economy. While inventions (the discovery of new products, ideas, and production processes) may be the result of accident and creativity unrelated to economics, innovations (the implementation of the inventions) are induced by economic activity, and can be divided into product and process innovations. Product innovations introduce new products and often involve the formation of new industries, markets, and infrastructure. Process innovations are improved methods of providing existing products.

The distinction between product and process innovations is critical to the theory of long waves. Process innovations tend to occur during the upswing of a wave because existing products are highly profitable and businesses are more inclined to improve old products than to introduce new ones. In the downswing of a long wave as existing products reach the ends of their life-cycles and profitability declines, businesses are induced to introduce new products.

Process and product innovations are but one aspect of a more general pattern of long wave behavior. Booth (1986) refers to the activity of businessmen during the upswings and downswings of long waves as managerial and entrepreneurial behavior, respectively. His analysis found evidence of differential regional long waves based 
on this distinction between managerial and entrepreneurial activity. When the economy is in a period of prosperity, managerial activity maintains the status quo and keeps the existing machinery operating smoothly. When the economy enters a period of decline, entrepreneurial activity seeks to change the status quo and try something new. Booth argues that the wide incidence of managerial behavior, including the existence of such institutional constraints as labor unions, restricts the entrepreneurial behavior needed to induce a long wave upswing. Amos and Currier (1989) provide a broader theoretical analysis of the differential pattem of entrepreneurial and managerial behavior, arguing that many areas of socio-economic behavior, including innovative activity, are affected during the course of a long wave.

Entrepreneurial activity and the product innovations induced by the downswing of one long wave generate the upswing of the next wave. These are endogenous forces that move the economy from downswing to upswing. Managerial activity and the process innovations induced by the long wave upswing facilitate the innovation diffusion and completion of the innovation life-cycle, and shift the economy from upswing to downswing. The seeds of each phase of the long wave are sown endogenously in the preceding phase, as the economy moves through the long cycle.

\section{Long Waves and Unbalanced Regional Growth}

The long wave theory offers an explanation for the unbalanced regional growth and increases in regional inequality observed in the 1970s. Although there are many conceptual similarities between the relationships identified in the regional growth theories and in the long wave theory, the latter incorporates a critical improvement that can explain endogenous growth. The fundamental deficiency of existing regional growth theories is their inability to explain increasing regional inequality without reference to exogenous changes in resource endowments, technological innovations, or political activity.

The long wave theory presented by van Duijn relies on technological innovations as an explanation for renewed growth and subsequent increases in regional income inequality. The relationship between long waves and unbalanced regional growth can be made explicit by incorporating the spatial dimension into the long wave theory. A synthesis of the regional growth and long wave theories, points out three key similarities and two critical differences.

All of these theories identify a central role for innovations in generating major industries that stimulate activity in the rest of the economy. Such industries are termed motor industries, export base industries, or leading sectors by the various theories used. The fundamental concept of a primary force driving the economy is the same in each case.

Theories also identify the multiplicative interaction between the driving industries and the rest of the economy. This interaction includes the multiplier effect, the spread effect, and factor mobility. Similarly, the theories recognize the importance of rapid, even cumulative, growth in the increasing portion of the innovation life-cycle, increasing returns to scale, and agglomeration economies. They highlight the central role of transportation systems in the development process. In the long wave and growth pole theories, transportation is a means of diffusing innovations and development through the innovation life-cycle and the spread effect. As North (1955, p. 248) indicates in his discussion of the economic base theory, improved transportation is tantamount to development.

The two critical differences between the regional growth theories and the long wave theory, is that the former do not make the process of development endogenous, while the latter does not consider the spatial dimension. The primary deficiency in all of the regional growth theories is their failure to explain a resurgence in growth without reference to exogenous occurrences. Such events are a central feature of the long wave theory. A new surge of development, rather than being explained away by exogenous shocks, actually is expected in the long wave theory.

The central deficiency of the long wave theory is its lack of an explicit spatial dimension. The innovation lifecycle implies that innovations are diffused not only temporally, but also spatially. Although the specific mechanism for this diffusion is not addressed in the long wave theory, the regional growth theories offer an appropriate mechanism in the spread effect.

In fact, a synthesis of the long wave and growth pole theories offers a more complete explanation of economic growth and development than either theory alone. Beginning at the bottom of a development cycle, entrepreneurial activity is stimulated by economic conditions to develop new product innovations that subsequently stimulate the upswing of the next wave. Moreover, the innovations lead to the creation of new industries or the rebirth of existing industries. These industries are not uniformly dispersed throughout the economy, but are concentrated in specific regions, often due to critical resources that are distributed heterogeneously across space. Moreover, within regions, the leading industries are concentrated at specific locations. If the new leading industries are not located initially in major urban areas, capital investments, especially in transportation systems, are likely to create urban areas. In growth pole terminology, the product innovations create growth poles for the entire economy and growth centers 
within specific regions. The innovation life-cycle diffusion process, including the infrastructure investment stimulated and the overall economic activity generated by the multiplier process, is seen in the growth pole theory as the spread effect. Development is diffused throughout the economy through the growth poles and growth centers.

As the innovation life-cycles near completion, development is spread from growth centers to peripheral areas and the long wave begins to stagnate or decline, motivating new product innovations. At the start of another long wave, the growth pole process, including unbalanced growth and increasing regional income inequality, begins once more, but from a higher overall level of development. However, the growth poles for the new product innovations need not be in the same locations as the earlier poles. The locations of the new growth poles will depend on the nature of the new products stimulating the process and the resources required in their production. If resources have been depleted in the production of earlier products, the innovations will be likely to rely on new resources at different locations. Institutional constraints, depreciated capital, and other impediments to growth at the earlier poles also are likely to induced the emergence of new poles at different locations.

The urban hierarchy plays a key role in this process, acting to diffuse the new products spatially innovations driving the long wave. Given that the economic distance between urban centers typically is less than the geographic distance, innovations spread across the country from one urban center to another center lower in the hierarchy. Each urban center also acts to diffuse the innovation in its local, area. The diffusion down the urban hierarchy initially generates a hierarchial backwash effect as growth in lower urban centers is inhibited by that in higher centers. As the lower urban centers benefit from the spread effect, they induce a backwash effect on their peripheries and in other urban centers, even lower in the hierarchy. This process generates a temporal lag as the long wave is transmitted down the urban hierarchy.

Booth (1986) points out that different regions are likely to be in different phases of a long wave at any given time. This is logical, considering the diffusion of development in the context of the spatial interaction growth poles. Regions containing the leading sectors stimulating the current long wave will grow earlier and faster than other regions. Development will spread to the periphery of the regional growth center while it also is spreading down the urban hierarchy. There will be lags between peripheral areas surrounding urban areas lower in the hierarchy and those around areas higher up. Where innovations and development are initiated in major urban areas on the east coast of the United States, a lag of several years would be expected before smaller urban areas in the central plains would be able to diffuse the activity to theirperipheral areas.

\section{A Reinterpretation of Increasing Regional Income Inequality}

Although existing regional growth theories resort to exogenous shocks to explain increasing economic inequality, the long wave theory indicates that this phenomenon is precisely what is expected when a new wave begins. As major product innovations, perhaps based on computer technology, are initiated, growth poles stimulate unbalanced regional growth across the nation. The unbalanced growth causes increases in-both interstate and intrastate inequalities.

An extension of Van Duijn's (1983) analysis places the bottom of the most recent long wave at 1982. Although his data end in 1973, comparison with previous cycles would indicate a decade long depression, ending about 1982 , followed by a decade of recovery and two decades of growth. The existence of increasing intrastate and interstate inequality during the mid-1970s is consistent with this overall timing of the long wave process.

The onset of a long wave upswing is expected to generated increasing interstate and intrastate inequality. The emergence of spatially concentrated growth poles initially will generate limited intrastate inequality as a small number of larger urban areas grow relatively faster than the surrounding rural peripheries and smaller cities. The overall growth of states containing the growth poles relative to that of states yet to be affected by the diffusion process also generates increasing interstate inequality. As diffusion progresses through the urban hierarchy, other states experience the increasing intrastate inequality, that results from differential urban-rural growth.

This explains the divergence of intrastate MIN values presented in Table 2 for each state, and their relationship to the "bottoming out" year for interstate inequality in Table 1. Although interstate inequality reached a minimum in 1978, 30 states reached a minimum intrastate inequality prior to that, and 20 either reached a minimum later or had no estimated minimum value. This indicates that the long wave growth process induced differential growth rates among urban-rural areas in many states during the early 1970s, with corresponding increases in intrastate inequality, and it also induced differential state growth rates, with corresponding increases in interstate inequality. Given that several states had exhibited no sign of increasing intrastate inequality as of 1983 , while other states experienced increasing inequality during the early 1970 s, it is evident that the temporal lag through the urban 
hierarchy is at least a decade, and perhaps longer. Since the incidence of increasing inequality indicated by Tables 1 3 is only one aspect of the long wave process, the time frame associated with the complete process clearly is several decades and consistent with the occurrence of endogenously generated 50-year long waves.

The world-wide nature of the long wave process also indicates why Australia also has signs of increasing inequality. There is no reason to believe the long wave spatial diffusion process is confined to national boundaries. The mechanism that has generated increasing regional inequality in the U. S. undoubtedly has generated increasing inequality in Australia. This suggests that other industrialized countries probably have experienced increasing inequality. Further study in this regard clearly is warranted.

Extending consideration of the international dimension of this process implies that the emergence of Japan as a major economic power in recent years very well may be a result of the long wave process. Given that growth poles are established by the introduction of major new products underlying the long wave, the development of silicon chips and their use in various electronic and computer products in the past $\mathbf{1 5}$ years is consistent with the emergence of Japan. Moreover, Tokyo also has become the premier world financial center, surpassing New York in this regard, and providing evidence that growth poles are likely to emerge at new locations due to differences in the underlying innovations. Whereas London and New York have been at the top of the world urban hierarchy for centuries, Tokyo appears to have taken over this spot in recent years. The diffusion of economic activity down the world-wide urban hierarchy, reaching U.S. and Australian cities in the past decade, is consistent with increasing inequality experienced by both countries. Although these thoughts are speculative and require further empirical analysis, they are consistant with the comprehensive and endogenous nature of the long wave explanation discussed here. Conventional theories of regional growth do not provide the same breadth or depth of explanation.

\section{Conclusions and Implications}

Theories traditionally used to explain patterns of regional growth fail to account adequately for recently observed increases in regional inequality in the United States. This inadequacy is due largely to the incompleteness of the theories, with each one capturing only partial aspects of the regional growth process. A major deficiency of existing regional growth theories, failure to incorporate endogenous initiation of the growth process, is corrected in the theory of long waves. The theory of long waves, while including the important roles of growth pole industries, the multiplier process, increasing returns to scale, diffusion, and transportation investment, all highlighted by existing theories, is based on induced technological innovations initiating the growth process. In this theory technological innovations are induced when products generated by previous innovations have been diffused throughout the economy and markets become saturated.

Evidence of increasing regional income inequality in the 1970s is consistent with the spatial long wave process. The long wave theory indicates that increasing regional inequality, occurring after decades of decline, is caused by a pattern of long waves stimulated by major product innovations. The spatial long wave process can explain both interstate and intrastate inequality and it implies international patterns of income inequality and uneven growth.

Further theoretical analysis and empirical tests obviously are necessary to validate this explanation of increasing regional inequality. However, since the observed phenomenon is inadequately explained by existing regional growth theories there is reason to explore this explanation, an activity that can only improve understanding of the regional growth process. If the explanation generated by the long wave theory proves valid, it will generate new insight into regional development policies. Although regional leaders and policy-makers historically have sought to attract economic base industries as a means of promoting growth and development, the long wave theory adds specificity to this pursuit. In particular, the regional economies that benefit most from an ensuing wave are those that are based on the major product innovations leading the wave. There clearly is an important reason to investigate further the nature of past long waves to determine their composition and thus to project the characteristics of future waves.

\section{References}

Alonso, William. "Five Bell Shapes in Development." Regional Science Association Papers. 45 (1980). 5-16.

Amos, Orley M. "Unbalance Regional Growth and Regional Income Inequality in the Latter Stages of Development." $\mathrm{Re}$ gional Science and Urban Economics. 18 (1988). 549-566. and Kevin M. Currier. "The Foundations of a Hierarchial Theory of the Long-Wave Phenomenon." Southern Economic Joumal. 56 (1989). 142-156.

Booth, Douglas E. "Long Waves and Uneven Regional Growth." Southern Economic Journal. 53 (1986). 448-460.

Borts, George H. "The Equalization of Returns and Regional Economic Growth." American Economic Review. 50 (1960). 319-347. 
and Jerome L. Stein. Economic Growth in A Free Market.

New York: Columbia University Press, 1964.

Chenery, H. B. "Development Policies for Southern Italy." Quarterly Journal of Economics. 76 (1962). 515-547.

Dixon, R. and A. P. Thirlwall. "A Model of Regional GrowthRate Differences on Kaldorian Lines." Oxford Economic Papers. 27 (1975). 201-214.

Friedenberg, Howard L. "Regional Differences in Personal Income Growth, 1929-77." Survey of Current Business. U.S. Department of Commerce, Bureau of Economic Analysis. 58 (October 1978). 27-31.

Greenwood, Michael J. "Research on Internal Migration in the United States: A Survey." Journal of Economic Literature. 13 (1975). 397-433.

"Human Migration: Theory, Models, and Empirical Studies." Journal of Regional Science. 25 (1985). 521544.

Hansen, Niles M. "Development Pole Theory in a Regional Context." Kyklos. 20 (1967). 709-725.

Hartman, L. M. and David Seckler. "Toward the Application of Dynamic Growth Theory to Regions." Journal of Regional Science. 7 (1967). 167-173.

Hirschman, Albert O. "Interregional and International Transmission of Economic Growth." In The Strategy of Economic Development. New Haven, Connecticut: Yale University Press, 1958. 183-201.

Hughes, J. R. "Interregional Income Differences: Self Perpetuation." Southern Economic Journal. 28 (1961). 4145.

Johnson, K. P. and Howard L. Friedenberg. "Regional and State Projections of Income. Employment, and Population to the Year 2000." Survey of Current Business. U.S. Department of Commerce, Bureau of Economic Analysis. 65 (May 1985). 39-48.

Kaldor, Nicholas. "The Case for Regional Policies." Scottish Joumal of Political Economy. 17 (1970). 337-347.

"A Model of Economic Growth." Economic Journal. (1957). 591-624.

Kitchin, Joseph. "Cycles and Trends in Economic Factors." Review of Economics and Statistics. 5 (1923). 10-15.

Klotz, Benjamin P. and Larry Neal. "Spectral Analysis of the Long-Swing Hypothesis." The Review of Economics and Statistics. (1973). 291-298.

Kondratieff, Nikolai D. The Long Wave Cycle. 1926. Translated by Guy Daniels. New York: Richardson and Snyder, 1984. "The Long Waves in Economic Life." The Review of Economics and Statistics. 17 (1935). 105-115.

Kuznets, Simon. Secular Movements in Production and Prices. New York: Houghton Mifflin, 1930.

"Economic Growth and Income Inequality." American Economic Review. 45 (1955). 1-28.

Lande, Paul S. and Peter Gordon. "Regional Growth in the
United States: A Reexamination of the Neoclassical Model." Journal of Regional Science. 17 (1977). 61-69.

Lasuen, J. R. "Regional Income Inequalities and the Problems of Growth." Regional Science Association Papers. 8 (1962). 169-188.

"On Growth Poles." Urban Studies. (1969). 137-161.

Maxwell, Philip and Robert Hale. "Income Inequality in Small Regions: Recent Trends in Australia." Presented at the Southern Regional Science Association meetings, Morgantown, West Virginia. April 16, 1988.

and Matthew Peter. "Income Inequality in Small Regions: A Study of Australian Statistical Divisions:" The Review of Regional Studies. 18 (1988). 19-27.

Mensch, G. Stalemate in Technology. Cambridge: Ballinger Publishing Company, 1979.

Myrdal, G. Economic Theory and Under-Developed Regions. London: Gerald Duckworth and Co., 1957.

North, Douglas C. "Location Theory and Regional Economic Growth." Journal of Political Economy. 58 (1955). 243 258.

Perroux, Francois. "Note sur la notion de 'pole de croissance?" Economie Appliqee. (1955). 307-320. Translated as "Note on the Concept of Growth Poles and reprinted in D. McKee, R.Dean, and W. Leahy (eds.). Regional Economics: Theory and Practice. New York: The Free Press, 1970. 93-104.

Pope, David. "Rostow's Kondratieff Cycle in Australia." Journal of Economic History. 44 (1984). 729-753.

Ray, Cadwell L. and R. Lynn Rittenoure. "Recent Regional Growth Patterns: More Inequality." Economic Development Quarterly. 1 (1987). 240-247.

Rostow, Walt W. "Kondratieff, Schumpeter and Kuznets: Trend Periods Revisited." Journal of American History. 25 (1975). 719-753.

Samuelson, Paul A. "Spatial Price Equilibrium and Linear Programming." American Economic Review. 42 (1952). 283-303.

Schumpeter, Joseph A. Business Cycles: A Theoretical, Historical, and Statistical Analysis of the Capitalist Process. Volumes I and II. New York: McGraw-Hill Book Company, Inc., 1939.

Smith, Donald M. "Neoclassical Growth Models and Regional Growth in the U.S." Journal of Regional Science. 14 (1975). 107-120.

Solow, Robert M. "A Contribution to the Theory of Economic Growth." Quarterly Journal of Economics. 70 (1956). 6594.

U. S. Bureau of Census. Current Population Reports. Series P60, No. 142. Money Income of Households, Families, and Persons in the United States, 1982." Washington, D.C.: U. S. Government Printing Office, 1984.

van Duijn, Jacob J. The Long Wave in Economic Life. London: George Allen and Unwin, 1983. 
van Ewijk, Casper. "A Spectral Analysis of the Kondratieff Cycle.” Kyklos. 35 (1982). 468-499.

Williamson, Jeffery G. "Regional Inequality and the Process of
National Development: A Description of the Patterns." Economic Development and Cultural Change. 13 (1965). 3-45. 